Int J Gynaecol Obstet. 2015 August ; 130(2): 137-141. doi:10.1016/j.ijgo.2015.02.026.

\title{
The increasing trend in preterm birth in public hospitals in northern Argentina
}

\author{
Emily H. Weaver ${ }^{a}{ }^{*}$, Luz Gibbons ${ }^{b}$, José M. Belizán ${ }^{b}$, and Fernando Althabe ${ }^{b}$ \\ aCarolina Population Center, University of North Carolina School at Chapel Hill, Chapel Hill, NC, \\ USA \\ bDepartment of Maternal and Child Health, Institute for Clinical Effectiveness and Health Policy, \\ Buenos Aires, Argentina
}

\begin{abstract}
Objective-To identify factors associated with the increasing incidence of preterm birth in northern Argentina.

Methods-In an observational study, data were reviewed from a prospective, population-based registry of pregnancy outcomes in six cities in 2009-2012. The primary outcome was preterm birth (at 20-37 weeks). Bivariate tests and generalized estimating equations were used within a conceptual hierarchical framework to estimate the cluster-corrected annual trend in odds of preterm birth.
\end{abstract}

Results-The study reviewed data from 11433 live births. There were 484 (4.2\%) preterm births. The incidence of preterm births increased by 38\% between 2009 and 2012, from 37.5 to 51.7 per 1000 live births. Unadjusted risk factors for preterm birth included young or advanced maternal age, normal body mass index, nulliparity, no prenatal care, no vitamins or supplements during pregnancy, multiple gestation, and maternal hypertension or prepartum hemorrhage. The prevalence of many risk factors increased over the study period, but variations in these factors explained less than $1 \%$ of the increasing trend in preterm birth.

Conclusion-The incidence of preterm births in six small cities in northern Argentina increased greatly between 2009 and 2012. This trend was unexplained by the risk factors measured. Other factors should be assessed in future studies.

\section{Keywords}

Argentina; Preterm birth; Trend

\footnotetext{
"Corresponding author: Emily H. Weaver, Carolina Population Center, University of North Carolina at Chapel Hill, 400 Meadowmont Village Circle, Chapel Hill, NC 27517, USA. Tel.: +1 919445 9350; fax: +1 919445 9353. emweaver@email.unc.edu.

Publisher's Disclaimer: This is a PDF file of an unedited manuscript that has been accepted for publication. As a service to our customers we are providing this early version of the manuscript. The manuscript will undergo copyediting, typesetting, and review of the resulting proof before it is published in its final citable form. Please note that during the production process errors may be discovered which could affect the content, and all legal disclaimers that apply to the journal pertain.

Conflict of interest

The authors have no conflicts of interest.
} 


\section{Introduction}

Improving birth outcomes has been a global priority for many years, with a focus on decreasing neonatal morbidity and mortality by increasing access to skilled healthcare providers. Preterm birth is the leading direct cause of neonatal mortality, resulting in 1 million newborn deaths annually [1]. Historically, preterm birth rates have been highest in low- and middle-income countries [2]. In the past three decades, however, the rate of preterm births has been rising in some middle- and high-income countries despite a high level of access to health services [2,3].

Spontaneous preterm labor and subsequent preterm birth are thought to be caused by a small number of mostly asymptomatic pathologies that might be influenced by internal and external maternal factors, including genetic, environmental, behavioral, and socioeconomic factors. Preterm elective induction or cesarean delivery could also be influenced by maternal or fetal risk factors and indications, the healthcare system, provider preferences, or imprecise estimates of gestational age [3-6]. Thus, research on the role of health systems and sociodemographic factors related to preterm birth might provide insight into the prevention of preterm births [7].

A rise in the prevalence of preterm birth is concerning not only because prematurity accounts for an average of 35\%, and up to $65 \%$, of deaths in the first 4 weeks of life [8], but also because surviving preterm neonates often require costly intensive care and are at increased risk of medium- and long-term health and developmental problems [2]. Thus, identifying factors associated with an increasing rate of preterm birth is crucial for both developing policies and implementing targeted and contextually appropriate interventions to reverse the trends $[4,7]$. Northern Argentina is one region where preterm birth rates have been rising despite universal access to maternity care even among disadvantaged populations [9].

The aim of the present study was to identify factors associated with the increasing trend in preterm birth in six small cities in Argentina.

\section{Materials and methods}

The present observational study reviewed secondary survey data from a prospective population-based registry of maternal and neonatal health outcomes in the Corrientes and Santiago del Estero provinces of Argentina between January 1, 2009, and December 31, 2012 [10,11]. This registry was compiled by the Global Network for Women's and Children's Health Research in Argentina (henceforth, Global Network) to identify all pregnant women and record pregnancy outcomes up to 6 weeks after delivery. Women provided informed consent for inclusion at the time of delivery. Detailed information about study design and ethics procedures have been described elsewhere [10,11].

The present study used data from six Global Network study clusters, which were randomly selected from two provinces in Argentina. Each cluster comprised a small city in the interior of the country with approximately 500 deliveries per year. Information was collected in public hospitals at the time of delivery from women and their hospital records. Self-reported 
information on prenatal care was collected retrospectively at the time of enrollment. For the present analysis, data from the partial years 2008 and 2013 and pregnancies that ended in spontaneous abortion, were medically terminated, or had missing data were excluded.

The primary study outcome was preterm birth, which was defined as any singleton or multiple live birth occurring at a gestational age of 20-37 weeks [1]. All study hospitals used either date of last menstrual period or ultrasonography for gestational age assessment, recording the best obstetric estimate on the basis of the information available. Time trends were assessed by calendar year of birth.

Because preterm birth is determined by multiple factors, some of which directly influence this outcome (e.g. genetics and maternal health) and some of which have a more complex effect (e.g. socioeconomic influences), preterm birth was modeled via a conceptual hierarchical framework first introduced by Victora et al. [12]. This framework was used to identify and depict the multiple levels of influence on preterm birth, and to consider the different levels of potential intervention.

Potential risk factors associated with the trend in preterm birth were controlled for via a four-level framework (Figure 1): level 1 was maternal characteristics, including maternal age, education, and pre-pregnancy body mass index (BMI, calculated as weight in kilograms divided by the square of height in meters); level 2 was reproductive history, including parity and last delivery outcome; level 3 was current or index pregnancy characteristics, including receipt of prenatal care, prenatal vitamins or iron supplements, multiple pregnancy, any evidence of hypertensive disease in pregnancy (e.g. severe pre-eclampsia or eclampsia), and prepartum hemorrhage; and level 4 was delivery characteristics represented by mode of delivery. Maternal characteristics, the highest level in the framework, included factors that might directly influence preterm birth or act through a number of other, more proximate risk factors in levels 2, 3, and 4 to influence preterm birth. Similarly, risk factors in level 2 might also influence preterm birth directly or through risk factors in levels 3 and 4 , and so on. This conceptual hierarchical framework was constructed using knowledge of the demographic and biological determinants of preterm birth.

Data analysis was carried out using Stata version 13 (StataCorp, College Station, TX, USA). Overall descriptive statistics were generated for factors associated with preterm birth, and the incidence of preterm birth within subgroups was tabulated. The bivariate relationship between each risk factor and preterm birth was assessed by estimating the unadjusted odds ratio of preterm birth for each high-risk subgroup as compared with the low-risk reference group. Descriptive statistics were then generated by year, and Royston $\chi^{2}$ test for linear trend of categorical variables was used to identify trends.

The odds of preterm birth was adjusted by modeling preterm birth on time and one risk factor at a time, and then the percentage difference in the annual mean odds of preterm birth was calculated for each model versus the time-only adjusted model to gauge the contribution of each factor independent of time. Lastly, by using factors associated with preterm birth, the fully adjusted change in odds of preterm birth per year was estimated via a generalized estimating equation that facilitated within-cluster correlation of the error terms. 
The results were generated in a multistep process, beginning with the time-adjusted annual change in odds of preterm birth and then sequentially adding risk factors within each level of the hierarchical model to evaluate how factors at each level might have accounted for the trend in preterm birth. A threshold of a 10\% change in odds was predetermined as a meaningful change in the adjusted odds of preterm birth versus the time-only adjusted trend. Because many birth records had missing information on maternal pre-pregnancy BMI and last pregnancy outcome (owing to nulliparity), these indicators were omitted from the final generalized estimating equation analyses. $P<0.05$ and $95 \%$ confidence intervals (CIs) were used to assign statistical significance.

\section{Results}

During the study period, there were 11433 live births that met the inclusion criteria, with $484(4.2 \%)$ preterm births. The final generalized estimating equation analyses included 10 759 live births; there were 425 (4.0\%) preterm births with complete data. Figure 2 shows the trends in delivery outcomes in the study sample between 2009 and 2012. The incidence of preterm birth increased from 37.5 to 51.7 per 1000 live births. The rate of stillbirths and neonatal deaths also increased over time; however, the sample size did not facilitate an analysis of these trends. The incidence of multiple pregnancies did not change over the study period.

Table 1 presents descriptive statistics by level of the hierarchical model, in addition to the prevalence of preterm birth and its relationship with each factor. The sample comprised women who were mainly 20 years or older, had completed primary school, and mostly had other children. Prenatal care was almost universal and rates of pregnancy complications were low. Overall, 3724 (32.6\%) women delivered by cesarean. Subpopulations with the highest incidence of preterm birth were those women who did not receive any prenatal care, did not receive prenatal vitamins or iron supplements, had a multiple pregnancy, or a complication in pregnancy (Table 1).

Risk factors associated with preterm birth included maternal age less than 20 years and at least 30 years, normal BMI $(18.5$ to $<25)$, nulliparity, no prenatal care, no prenatal supplementation of vitamins or iron, multiple pregnancy, and either hypertension or prepartum hemorrhage in the index pregnancy (Table 1).

Table 2 shows the trend in the main risk factors for preterm birth over time. Notably, the proportion of births to adolescents increased from $26.5 \%$ to $28.5 \%$ over the study period, while the frequency of births to nulliparous women also increased from $30.2 \%$ to $36.4 \%$. Although most characteristics of women in the index pregnancy did not exhibit a linear trend, the proportion of women without prenatal care decreased from $6.0 \%$ to $4.4 \%$, and the percentage of women with hypertension increased from $2.6 \%$ to $4.0 \%$. Over the study period, the rate of preterm birth increased $37.9 \%$, from $3.7 \%$ to $5.2 \%$, and that of cesarean delivery increased $44.3 \%$, from $26.4 \%$ to $38.1 \%$.

In a series of regression analyses of preterm birth on time, adjustment was made for one risk factor at a time to evaluate the percentage difference in the odds of preterm birth each year 
after adjustment for that risk factor as compared with no adjustment. The percentage difference in the odds of preterm birth each year did not change in either direction by more than $2 \%$ after adjustment for any single risk factor except for not receiving prenatal vitamins or iron, which resulted in a $2.9 \%$ increase in the odds of preterm birth each year (results not shown).

Similarly, changes in the odds of preterm birth each year were compared after adjusting sequentially for risk factors grouped by level of influence within the conceptual hierarchical framework. The "time" term in these models essentially captured the increase in the trend of preterm birth that was not taken into account by other risk factors as they were added to the model in groups according to their level in the conceptual hierarchical framework.

Adjustment for these risk factors jointly as groups (i.e. by level of influence) did not result in a meaningful change in the odds of preterm birth each year (i.e. >10\%); overall, when adjusting for all four levels of influence in the conceptual hierarchical framework, the corresponding risk factors accounted for less than $1.0 \%$ of the increasing trend in preterm birth over the years 2009-2012 (data not shown).

Results from a sensitivity analysis for the subgroup of nulliparous women did not substantially alter the increase in the odds of preterm birth. In a further analysis including BMI, the increase in odds of preterm birth was $7 \%$ per year (odds ratio 1.07 ; 95\% CI 0.951.21 ) in the fully adjusted model, which, although lower than the final estimate in the present study, was less than the a priori threshold for a meaningful difference (a 10\% change in odds).

\section{Discussion}

The present study attempted to identify factors associated with the increasing incidence of preterm births in six small cities in Argentina's interior. The findings show that preterm births increased 38\% during the study period. Most of the risk factors identified in the theoretical framework were also significantly associated with preterm birth, but when fully adjusted, the variation in these factors did not explain the increasing frequency in preterm birth at a meaningful level.

Few studies in low- and middle-income countries have provided such a high level of detail regarding facility-based births, and thus valuable information about determinants of preterm births in this context. Other major strengths of the present analysis are the high data quality and study design. Results are generalizable to public hospitals in the study region of Argentina, which typically serve socioeconomically disadvantaged populations who are without access to other health services.

As compared with national statistics that exhibited a decline in the preterm birth rate from $8.0 \%$ to $7.5 \%$ between 2009 and 2012 [13-16], the incidence of preterm birth in the study population was low, whereas the rate of change in preterm births was large. These findings highlight the marked variation in this outcome at a subnational level.

Data limitations prohibited the categorization of preterm births into additional subgroups, such as early or late, and medically indicated or spontaneous termination. Other potentially 
important factors known to be associated with preterm birth in other studies-e.g. maternal smoking and induction of labor-were omitted from the registry. In addition, many records lacked data on maternal pre-pregnancy BMI. Excluding BMI from the final models would introduce bias if this exclusion were to result in an increased estimate of the trend in preterm birth. However, a sensitivity analysis conducted on births with maternal BMI information revealed a decreased estimate of the trend in preterm birth, indicating that the women who lacked this missing information formed an important high-risk group.

Several studies in Canada, Denmark, and the USA have attributed changes in the rate of preterm birth to changes in observable factors such as early ultrasonography dating, both medically indicated and unindicated preterm delivery, preterm induction, cesarean delivery, fertility treatments, decreases in perinatal mortality and stillbirths, multiple births, and maternal demographic factors such as ethnic origin, age, and education [4,17-20]. Although it was not possible to measure some of the variables identified by these studies, it is clear that neither the maternal characteristics or process of care measures included in the present study, nor multiple births accounted for the increasing trend in preterm birth for these women. Therefore, relationships in this region of Argentina might vary from those identified in previous research. The rate of cesarean delivery rose markedly over the study period in the six cities, but after full adjustment, it also did not significantly account for the increasing incidence of preterm birth.

Some studies have suggested that the use of ultrasonography-based estimates of gestational age is related to increasing trends in preterm birth [17,19]. In the present study, ascertainment of gestational age at birth was done by clinically trained doctors and midwives. Thus, it seems unlikely that changes in the use of ultrasonography-based estimates contributed to the increasing rate of preterm birth observed; however, it is not possible to formally test this theory or rule out this possibility.

In a study in the USA by Chang et al. [4], half the rate of the increase in preterm births was attributable to unknown causes. This is also likely to be the case in Argentina; the increased prevalence of preterm birth could be due to unknown factors that were not addressed by the present study. One possibility is that individual risk factors or other unidentified determinants drove the change. Provider behavior could have also influenced the prevalence of preterm birth in ways that cannot be analyzed. For example, because survival for preterm babies has improved significantly, providers might feel more comfortable with aggressive treatment options for complicated pregnancies, although new evidence is mixed regarding this theory $[17,19,21,22]$. Nevertheless, if this behavior change occurred in the study population, it was not reflected in improved neonatal health outcomes.

In summary, the present study found that although many factors were associated with preterm birth in the present population, they did not jointly account for much of the increasing trend observed in preterm birth. More research is needed to identify and mitigate the factors driving this trend. 


\section{Acknowledgments}

The present work was funded by the Eunice Kennedy Shriver National Institute of Child Health and Human Development Global Network for Women's and Children's Health Research. E.H.W.'s fellowship was supported by the National Institutes of Health (NIH) Office of the Director; Fogarty International Center; Office of AIDS Research; National Cancer Center; National Heart, Blood, and Lung Institute; and the NIH Office of Research for Women's Health through the Fogarty Global Health Fellows Program Consortium comprising the University of North Carolina, John Hopkins, Morehouse, and Tulane (1R25TW009340-01), and the American Recovery and Reinvestment Act. Data collection was supported by the NIH (grant U01 HD058322/HD/NICHD; secondary source ID NCT01084096).

\section{References}

1. March of Dimes; PMNCH; Save the Children; World Health Organization. Born Too Soon: The Global Action Report on Preterm Birth. 2012 http://www.who.int/pmnch/media/news/ 2012/201204_borntoosoon-report.pdf. Published.

2. Lawn JE, Gravett MG, Nunes TM, Rubens CE, Stanton C, GAPPS Review Group. Global report on preterm birth and stillbirth (1 of 7): definitions, description of the burden and opportunities to improve data. BMC Pregnancy Childbirth. 2010; 10(Suppl 1):S1. [PubMed: 20233382]

3. Blondel B, Kogan MD, Alexander GR, Dattani N, Kramer MS, Macfarlane A, et al. The impact of the increasing number of multiple births on the rates of preterm birth and low birthweight: an international study. Am J Public Health. 2002; 92(8):1323-30. [PubMed: 12144992]

4. Chang HH, Larson J, Blencowe H, Spong CY, Howson CP, Cairns-Smith S, et al. Preventing preterm births: analysis of trends and potential reductions with interventions in 39 countries with very high human development index. Lancet. 2013; 381(9862):223-34. [PubMed: 23158883]

5. Gravett MG, Rubens CE, Nunes TM, GAPPS Review Group. Global report on preterm birth and stillbirth (2 of 7): discovery science. BMC Pregnancy Childbirth. 2010; 10(Suppl 1):S2. [PubMed: 20233383]

6. Kuehn BM. Scientists probe the role of clinicians in rising rates of late preterm birth. JAMA. 2010; 303(12):1129-1136. [PubMed: 20332392]

7. Norman JE, Shennan AH. Prevention of preterm birth--why can't we do any better? Lancet. 2013; 381(9862):184-5. [PubMed: 23158880]

8. Black RE, Cousens S, Johnson HL, Lawn JE, Rudan I, Bassani DG, et al. Global, regional, and national causes of child mortality in 2008: a systematic analysis. Lancet. 2010; 375(9730):1969-87. [PubMed: 20466419]

9. Blencowe H, Cousens S, Oestergaard MZ, Chou D, Moller AB, Narwal R, et al. National, regional, and worldwide estimates of preterm birth rates in the year 2010 with time trends since 1990 for selected countries: a systematic analysis and implications. Lancet. 2012; 379(9832):2162-72. [PubMed: 22682464]

10. Althabe F, Belizán JM, Mazzoni A, Berrueta M, Hemingway-Foday J, Koso-Thomas M, et al. Antenatal corticosteroids trial in preterm births to increase neonatal survival in developing countries: study protocol. Reprod Health. 2012; 9:22. [PubMed: 22992312]

11. Goudar SS, Carlo WA, McClure EM, Pasha O, Patel A, Esamai F, et al. The Maternal and Newborn Health Registry Study of the Global Network for Women's and Children's Health Research. Int J Gynecol Obstet. 2012; 118(3):190-3.

12. Victora CG, Huttly SR, Fuchs SC, Olinto MT. The role of conceptual frameworks in epidemiological analysis: a hierarchical approach. Int J Epidemiol. 1997; 26(1):224-7. [PubMed: 9126524]

13. Argentina National Ministry of Health. Vital Statistics: Basic Information - Year 2009 (in Spanish). Ministry of Health; Caracas: 2010.

14. Argentina National Ministry of Health. [Accessed July 25, 2014] Vital Statistics: Basic Information - Year 2010 (in Spanish). Dec. 2011 http://www.deis.gov.ar/publicaciones/archivos/ Serie5Nro54.pdfPublished 
15. Argentina National Ministry of Health. [Accessed July 25, 2014] Vital Statistics: Basic Information - Year 2011 (in Spanish). Dec. 2012 http://www.deis.gov.ar/publicaciones/archivos/ Serie5Nro55.pdfPublished

16. Argentina National Ministry of Health. Vital Statistics: Basic Information - Year 2012 (in Spanish). Ministry of Health; Caracas: 2013.

17. Kramer MS, Platt R, Yang H, Joseph KS, Wen SW, Morin L, et al. Secular trends in preterm birth: a hospital-based cohort study. JAMA. 1998; 280(21):1849-54. [PubMed: 9846780]

18. Ananth CV, Joseph KS, Oyelese Y, Demissie K, Vintzileos AM. Trends in preterm birth and perinatal mortality among singletons: United States, 1989 through 2000. Obstet Gynecol. 2005; 105(5 Pt 1):1084-91. [PubMed: 15863548]

19. Joseph KS, Kramer MS, Marcoux S, Ohlsson A, Wen SW, Allen A, et al. Determinants of preterm birth rates in Canada from 1981 through 1983 and from 1992 through 1994. N Engl J Med. 1998; 339(20):1434-9. [PubMed: 9811918]

20. Langhoff-Roos J, Kesmodel U, Jacobsson B, Rasmussen S, Vogel I. Spontaneous preterm delivery in primiparous women at low risk in Denmark: population based study. BMJ. 2006; 332(7547): 937-9. [PubMed: 16497733]

21. Lopez PO, Bréart G. Trends in gestational age and birth weight in Chile, 1991-2008. A descriptive epidemiological study. BMC Pregnancy Childbirth. 2012; 12:121. [PubMed: 23116061]

22. Bassil KL, Yasseen AS 3rd, Walker M, Sgro MD, Shah PS, Smith GN, et al. The association between obstetrical interventions and late preterm birth. Am J Obstet Gynecol. 2014; 210(6): 538.e1-9. [PubMed: 24582931] 


\section{Synopsis}

Between 2009 and 2012, the preterm birth rate increased by $38 \%$ in six small cities in Argentina. This trend was unexplained by measured risk factors. 


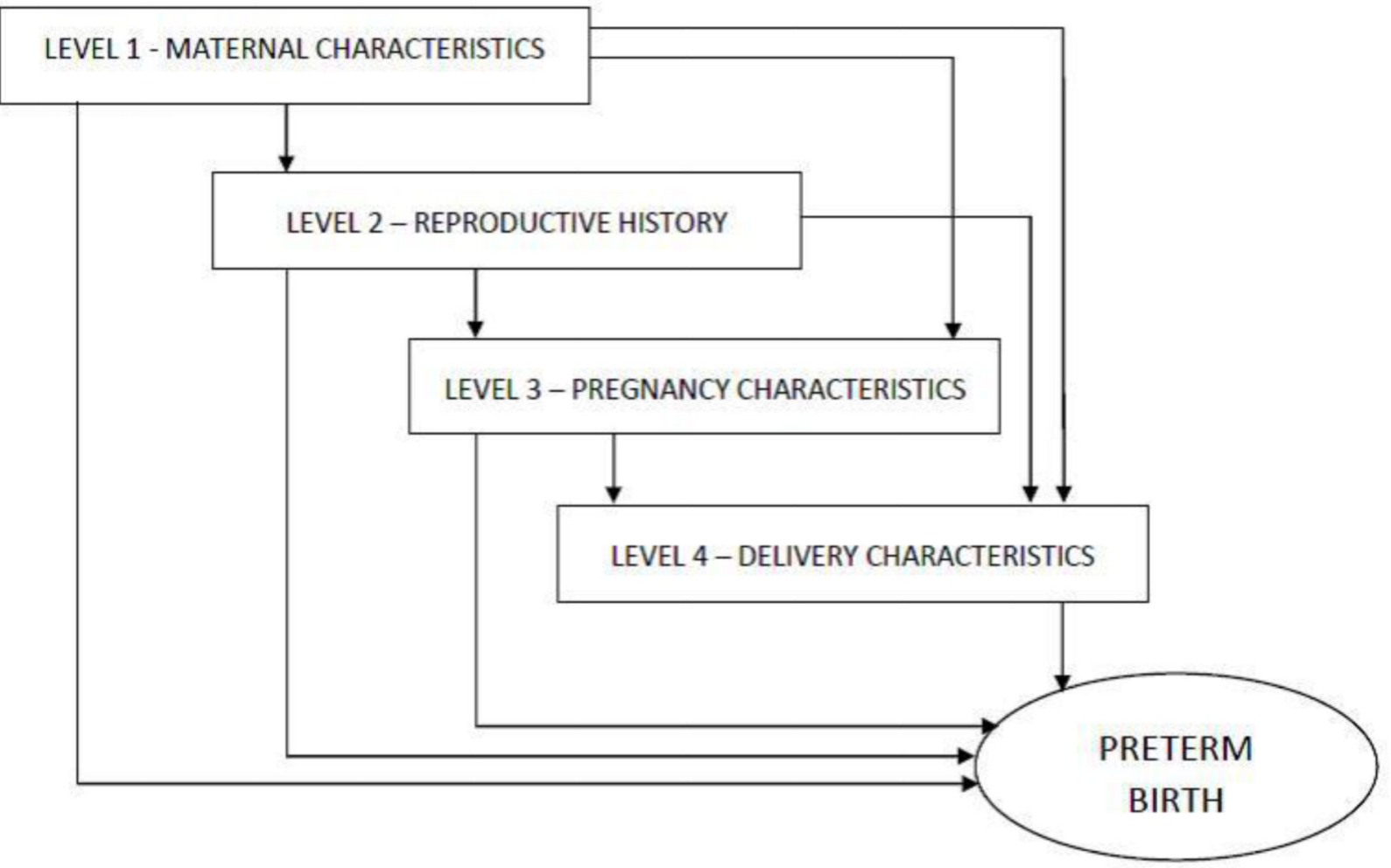

Figure 1.

Hierarchical model showing the factors associated with preterm birth by level. 


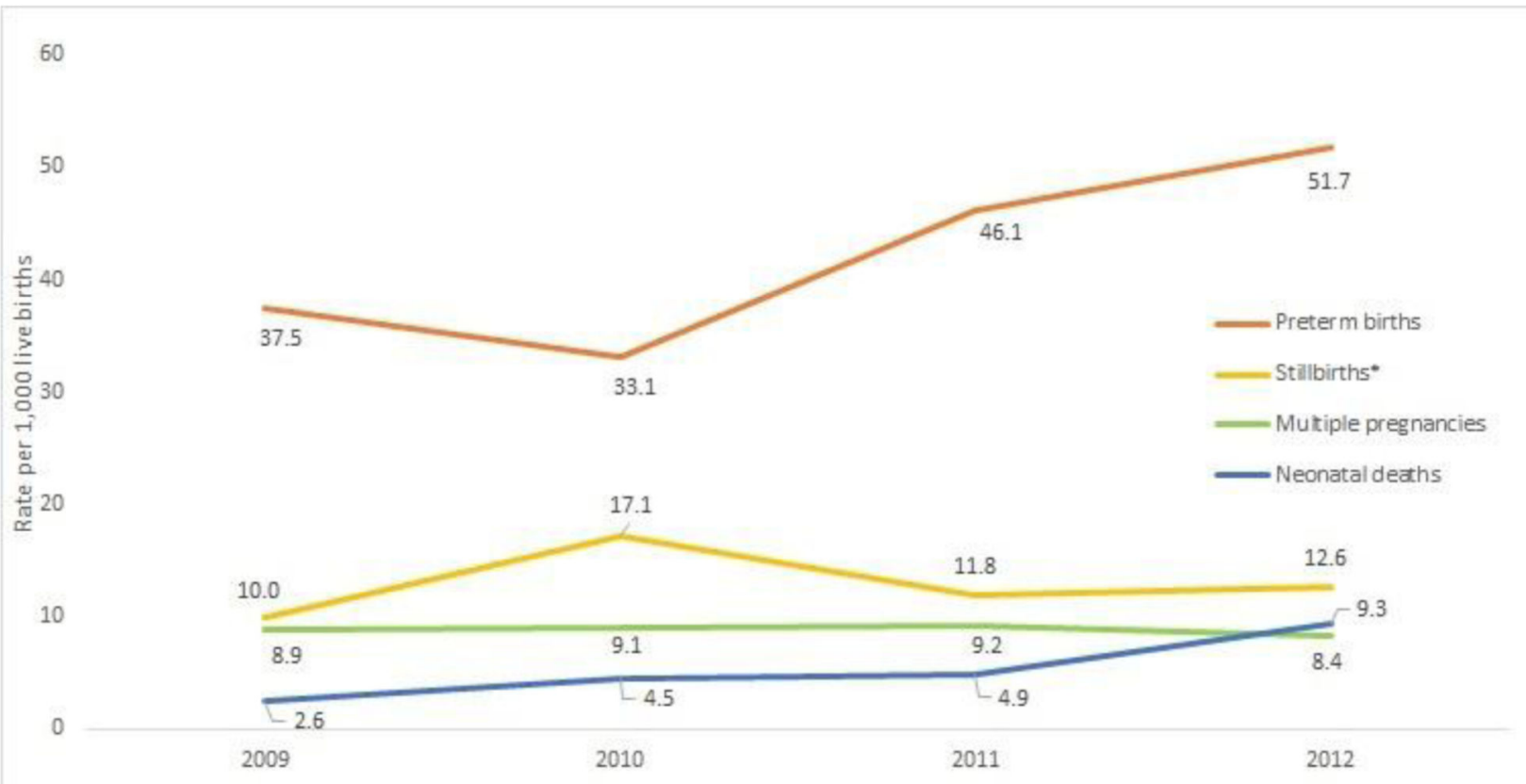

Figure 2.

Trends in selected birth outcomes in Global Network study sites in Argentina, by year. * Stillbirths per 1000 pregnancies. 


\section{Table 1}

Maternal and delivery characteristics, and frequencies and odd ratios of preterm birth among subgroups.

\begin{tabular}{|c|c|c|c|}
\hline \multirow[b]{2}{*}{$\begin{array}{l}\text { Characteristics by hierarchical } \\
\text { analysis }\end{array}$} & \multirow[b]{2}{*}{$\begin{array}{l}\text { Overall deliveries } \\
(\mathrm{n}=11 \mathrm{433})\end{array}$} & \multicolumn{2}{|c|}{ Preterm birth } \\
\hline & & $\begin{array}{l}\text { Frequency } \\
(\mathrm{n}=\mathbf{4 8 4})\end{array}$ & Odds ratio $(95 \% \mathrm{CI})$ \\
\hline \multicolumn{4}{|l|}{ Level 1: maternal characteristics } \\
\hline \multicolumn{4}{|l|}{ Age, $y$} \\
\hline$<20$ & $3076 / 11375(27.0)$ & $173 / 3076(5.6)$ & $1.69(1.43-2.00)$ \\
\hline $20-29$ & $5619 / 11375(49.4)$ & $191 / 5619(3.4)$ & Ref. \\
\hline$\geq 30$ & $2680 / 11375(23.6)$ & $118 / 2680(4.4)$ & $1.31(1.01-1.69)$ \\
\hline \multicolumn{4}{|l|}{ Education level } \\
\hline Less than primary & 2124/11 $211(18.9)$ & $107 / 2124(5.0)$ & $1.27(0.96-1.67)$ \\
\hline Completed primary & $9087 / 11211(81.1)$ & $365 / 9087(4.0)$ & Ref. \\
\hline \multicolumn{4}{|l|}{ BMI } \\
\hline$<18.5$ & $217 / 7485(2.9)$ & $8 / 217(3.7)$ & $0.798(0.46-1.38)$ \\
\hline 18.5 to $<25$ & $3103 / 7485(41.5)$ & $142 / 3103(4.6)$ & Ref. \\
\hline$\geq 25$ & $4165 / 7485(55.6)$ & $107 / 4165(2.6)$ & $0.549(0.45-0.68)$ \\
\hline \multicolumn{4}{|l|}{ Level 2: maternal history } \\
\hline \multicolumn{4}{|l|}{ Parity } \\
\hline 0 & $3686 / 11377(32.4)$ & $192 / 3686(5.2)$ & $1.43(1.29-1.58)$ \\
\hline$\geq 1$ & $7691 / 11377(67.6)$ & $285 / 7691(3.7)$ & Ref. \\
\hline \multicolumn{4}{|l|}{ Last pregnancy outcome } \\
\hline Did not result in live birth & $111 / 7648(1.5)$ & $7 / 111(6.3)$ & $1.79(0.90-3.56)$ \\
\hline Resulted in live birth & $7537 / 7648(98.5)$ & $273 / 7537(3.6)$ & Ref. \\
\hline \multicolumn{4}{|l|}{ Level 3: pregnancy characteristics } \\
\hline \multicolumn{4}{|l|}{ Prenatal care visits } \\
\hline 0 & $599 / 11341(5.3)$ & $78 / 599(13.0)$ & $4.0(2.52-6.34)$ \\
\hline$\geq 1$ & $10742 / 11341(94.7)$ & $388 / 10742(3.6)$ & Ref. \\
\hline \multicolumn{4}{|l|}{ Prenatal vitamins } \\
\hline $\begin{array}{l}\text { Did not receive vitamins or iron } \\
\text { supplements }\end{array}$ & $1666 / 11166(14.9)$ & $144 / 1666(8.6)$ & $2.84(1.91-4.24)$ \\
\hline Received vitamins & $9500 / 11166(85.1)$ & $306 / 9500(3.2)$ & Ref. \\
\hline \multicolumn{4}{|l|}{ Pregnancy type } \\
\hline Multiple & $100 / 11403(0.9)$ & $32 / 100(32.0)$ & $11.3(7.01-18.28)$ \\
\hline Single & $11303 / 11403$ (99.1) & $451 / 11303(4.0)$ & Ref. \\
\hline \multicolumn{4}{|l|}{ Pregnancy complications } \\
\hline \multicolumn{4}{|l|}{ Hypertension } \\
\hline Yes & $389 / 11349(3.4)$ & $58 / 389(14.9)$ & $4.4(2.90-6.64)$ \\
\hline No & $10960 / 11349$ (96.6) & $421 / 10960(3.8)$ & Ref. \\
\hline \multicolumn{4}{|l|}{ Prepartum hemorrhage } \\
\hline Yes & $63 / 11242(0.6)$ & $16 / 63(25.4)$ & $8.0(4.20-15.19)$ \\
\hline No & 11 279/11 342 (99.4) & $461 / 11279(4.1)$ & Ref. \\
\hline
\end{tabular}

Int J Gynaecol Obstet. Author manuscript; available in PMC 2016 August 01. 


\begin{tabular}{llll}
\hline \multirow{2}{*}{$\begin{array}{l}\text { Characteristics by hierarchical } \\
\text { analysis }\end{array}$} & $\begin{array}{l}\text { Overall deliveries } \\
(\mathbf{n = 1 1} 433)\end{array}$ & $\begin{array}{l}\text { Prequency } \\
\text { (n=484) }\end{array}$ & Odds ratio (95\% CI) \\
\hline Gestational age & & & - \\
237 wk (term) & $10949 / 11433(95.8)$ & - & - \\
$\quad<37$ wk (preterm) & $484 / 11433(4.2)$ & - & \\
$\begin{array}{c}\text { Type of delivery } \\
\text { Cesarean } \\
\text { Vaginal }\end{array}$ & $3724 / 11433(32.6)$ & $184 / 3724(4.9)$ & $1.28(0.92-1.80)$ \\
\hline
\end{tabular}

Abbreviations: CI, confidence interval; BMI, body weight index (calculated as weight in kilograms divided by the square of height in meters).

$a_{\text {Values are given as number/number for whom data were available (percentage). }}$

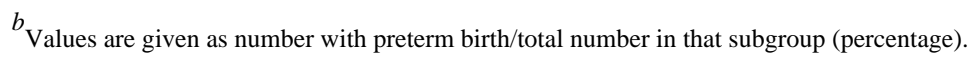


Table 2

Temporal trends in factors associated with preterm birth.

\begin{tabular}{|c|c|c|c|c|c|}
\hline \multirow{2}{*}{ Factors } & \multicolumn{4}{|c|}{ Preterm births ${ }^{a}$} & \multirow{2}{*}{$\begin{array}{l}P \\
\text { value }^{b}\end{array}$} \\
\hline & $\begin{array}{l}2009 \\
(n=2668)\end{array}$ & $\begin{array}{l}2010 \\
(n=2811)\end{array}$ & $\begin{array}{l}2011(n= \\
2995)\end{array}$ & $\begin{array}{l}2012 \\
(n=2959)\end{array}$ & \\
\hline \multicolumn{6}{|l|}{ Maternal characteristics } \\
\hline \multicolumn{6}{|l|}{ Age, y } \\
\hline$<20$ & $\begin{array}{l}699 / 2643 \\
(26.5)\end{array}$ & $\begin{array}{l}724 / 2799 \\
(25.9)\end{array}$ & $\begin{array}{l}814 / 2986 \\
(27.3)\end{array}$ & $\begin{array}{l}839 / 2947 \\
(28.5)\end{array}$ & 0.043 \\
\hline $20-29$ & $\begin{array}{l}1319 / 2643 \\
(49.9)\end{array}$ & $\begin{array}{l}1425 / 2799 \\
(50.9)\end{array}$ & $\begin{array}{l}1443 / 2986 \\
(48.3)\end{array}$ & $\begin{array}{l}1432 / 2947 \\
(48.6)\end{array}$ & 0.1161 \\
\hline 230 & $\begin{array}{l}625 / 2643 \\
(23.6)\end{array}$ & $\begin{array}{l}650 / 2799 \\
(23.2)\end{array}$ & $\begin{array}{l}729 / 2986 \\
(24.4)\end{array}$ & $\begin{array}{l}676 / 2947 \\
(22.9)\end{array}$ & 0.789 \\
\hline \multicolumn{6}{|l|}{ BMI } \\
\hline$<18.5$ & $\begin{array}{l}73 / 1798 \\
(4.1)\end{array}$ & $\begin{array}{l}80 / 1763 \\
(4.5)\end{array}$ & $\begin{array}{l}21 / 1883 \\
(1.1)\end{array}$ & $\begin{array}{l}43 / 2041 \\
(2.1)\end{array}$ & $<0.001$ \\
\hline 18.5 to $<25$ & $\begin{array}{l}775 / 1798 \\
(43.1)\end{array}$ & $\begin{array}{l}804 / 1763 \\
(45.6)\end{array}$ & $\begin{array}{l}723 / 1883 \\
(38.4)\end{array}$ & $\begin{array}{l}801 / 2041 \\
(39.2)\end{array}$ & $<0.001$ \\
\hline 225 & $\begin{array}{l}950 / 1798 \\
(52.8)\end{array}$ & $\begin{array}{l}879 / 1763 \\
(49.9)\end{array}$ & $\begin{array}{l}1139 / 1883 \\
(60.5)\end{array}$ & $\begin{array}{l}1197 / 2041 \\
(58.6)\end{array}$ & $<0.001$ \\
\hline \multicolumn{6}{|l|}{ Reproductive history } \\
\hline Nulliparous & $\begin{array}{l}797 / 2642 \\
(30.2)\end{array}$ & $\begin{array}{l}824 / 2800 \\
(29.4)\end{array}$ & $\begin{array}{l}995 / 2992 \\
(33.3)\end{array}$ & $\begin{array}{l}1070 / 2943 \\
(36.4)\end{array}$ & $<0.001$ \\
\hline \multicolumn{6}{|l|}{ Pregnancy characteristics } \\
\hline No prenatal care visits & $\begin{array}{l}159 / 2650 \\
(6.0)\end{array}$ & $\begin{array}{l}174 / 2797 \\
(6.2)\end{array}$ & $\begin{array}{l}137 / 2974 \\
(4.6)\end{array}$ & $\begin{array}{l}129 / 2920 \\
(4.4)\end{array}$ & 0.001 \\
\hline No prenatal vitamins or iron & $\begin{array}{l}448 / 2561 \\
(17.5)\end{array}$ & $\begin{array}{l}409 / 2744 \\
(14.9)\end{array}$ & $\begin{array}{l}305 / 2952 \\
(10.3)\end{array}$ & $\begin{array}{l}504 / 2909 \\
(17.3)\end{array}$ & 0.141 \\
\hline Multiple pregnancy & $\begin{array}{l}23 / 2657 \\
(0.9)\end{array}$ & $\begin{array}{l}26 / 2809 \\
(0.9)\end{array}$ & $\begin{array}{l}28 / 2987 \\
(0.9)\end{array}$ & $\begin{array}{l}23 / 2950 \\
(0.8)\end{array}$ & 0.742 \\
\hline Hypertension & $\begin{array}{l}67 / 2630 \\
(2.6)\end{array}$ & $\begin{array}{l}94 / 2801 \\
(3.4)\end{array}$ & $\begin{array}{l}111 / 2980 \\
(3.7)\end{array}$ & $\begin{array}{l}117 / 2938 \\
(4.0)\end{array}$ & 0.003 \\
\hline Prepartum hemorrhage & $9 / 2628(0.3)$ & $\begin{array}{l}13 / 2802 \\
(0.5)\end{array}$ & $\begin{array}{l}28 / 2976 \\
(0.9)\end{array}$ & $\begin{array}{l}13 / 2936 \\
(0.4)\end{array}$ & 0.234 \\
\hline \multicolumn{6}{|l|}{ Delivery characteristics } \\
\hline Preterm birth & $\begin{array}{l}100 / 2668 \\
(3.7)\end{array}$ & $\begin{array}{l}93 / 2811 \\
(3.3)\end{array}$ & $\begin{array}{l}138 / 2995 \\
(4.6)\end{array}$ & $\begin{array}{l}153 / 2959 \\
(5.2)\end{array}$ & $<0.001$ \\
\hline Caesarean delivery & $\begin{array}{l}704 / 2668 \\
(26.4)\end{array}$ & $\begin{array}{l}866 / 2811 \\
(30.8)\end{array}$ & $\begin{array}{l}1026 / 2995 \\
(34.3)\end{array}$ & $\begin{array}{l}1128 / 2959 \\
(38.1)\end{array}$ & $<0.001$ \\
\hline
\end{tabular}

Int J Gynaecol Obstet. Author manuscript; available in PMC 2016 August 01. 